\title{
Could Unsustainable Electronics Support Sustainability?
}

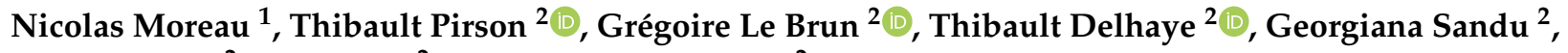 \\ Antoine Paris ${ }^{2}$, David Bol ${ }^{2}$ and Jean-Pierre Raskin ${ }^{2, *}$ \\ 1 IMCN/NAPS, Université Catholique de Louvain (UCLouvain), B-1348 Louvain-la-Neuve, Belgium; \\ nic.moreau@uclouvain.be \\ 2 ICTEAM/ELEN, Université Catholique de Louvain (UCLouvain), B-1348 Louvain-la-Neuve, Belgium; \\ thibault.pirson@uclouvain.be (T.P.); gregoire.lebrun@uclouvain.be (G.L.B.); \\ thibault.delhaye@uclouvain.be (T.D.); georgiana.sandu@uclouvain.be (G.S.); \\ antoine.paris@uclouvain.be (A.P.); david.bol@uclouvain.be (D.B.) \\ * Correspondence: jean-pierre.raskin@uclouvain.be
}

check for updates

Citation: Moreau, N.; Pirson, T.; Le Brun, G.; Delhaye, T.; Sandu, G.; Paris, A.; Bol, D.; Raskin, J.-P. Could Unsustainable Electronics Support Sustainability? Sustainability 2021, 13, 6541. https://doi.org/10.3390/ su13126541

Academic Editor: Adriana Del Borghi

Received: 20 April 2021

Accepted: 2 June 2021

Published: 8 June 2021

Publisher's Note: MDPI stays neutral with regard to jurisdictional claims in published maps and institutional affiliations.

Copyright: (c) 2021 by the authors. Licensee MDPI, Basel, Switzerland. This article is an open access article distributed under the terms and conditions of the Creative Commons Attribution (CC BY) license (https:// creativecommons.org/licenses/by/ $4.0 /)$.

\begin{abstract}
Information and communication technologies are often considered by policymakers, industrial stakeholders and scientists as a key lever in the run towards sustainability, since they should ease energy efficiency and dematerialization. In this opinion article, nurtured by the inputs of a broad panel of experts, we challenge this widely spread view by highlighting the detrimental social and environmental footprints caused by digital technologies. We further take a critical look on the ways innovation is conducted nowadays, i.e., with an almost exclusive focus on performance and few considerations for externalities. This leads us to call for academic teaching programs advocating for a holistic approach, for new business models, and for ambitious political decisions able to drive a paradigm shift in the mainstream agenda of electronics innovation and digital transition that shall significantly contribute to the well-being of everyone, everywhere, without compromising future generations. We conclude that digital technologies cannot support long-term sustainability if their only purpose remains the optimization of the current system.
\end{abstract}

Keywords: sustainability; electronics; environmental footprint; social responsibility; life cycle assessment (LCA); circular economy

\section{Introduction}

Climate scientists warn us that the more Earth's temperature rises due to greenhouse gases (GHG) emissions, the more humanity will face extreme weather events such as droughts, heat waves, floods, or hurricanes, threatening food safety and deepening economic disparities [1,2]. Furthermore, it increases the risk of overpassing tipping points, with, as a consequence, the impossibility to conserve the stable climate that allowed humankind to thrive for 10,000 years [3]. In 2015's Paris Agreement [4], most of Earth's countries agreed to stay below $2{ }^{\circ} \mathrm{C}$ of temperature rise compared to the pre-industrial levels. In order to avoid overpassing this limit, global GHG emissions should be reduced by half in 2030 and reach zero in 2050 [5]! Please take some time, step back and realize the size and the implications of the challenge: GHG emissions should be cut in half worldwide in the next 9 years, while $75 \%$ of worldwide population faces multidimensional deprivation [6] and aspires to raise their standard of living.

To take up this challenge, information and communication technologies (ICTs) are often considered as the silver bullet. For instance, the ambitious European Green Deal states: "Digital technologies are a critical enabler for attaining the sustainability goals of the Green deal in many different sectors" [7]. In this framework, digital transformation aims to optimize processes, manage the intermittent renewable energy networks and dematerialize the economy through new business models. However, a closer look into ICTs ${ }^{\prime}$ environmental footprint makes the story less enchanting, considering pollution generated through electronic devices' life cycle or the energy consumed by all the infrastructures used 
to store and transfer data across the globe. Hence, how can we ensure that ICTs are part of the solution rather than an extra burden in the urgent run towards a decarbonized world? Far from giving an exhaustive answer to this complex question, this opinion aims to give some lines of thinking to address it.

\section{Highlighting ICTs Ecological Footprint}

A clear overview of ICTs' environmental impacts, either positive or negative, is an unavoidable prerequisite before looking into solutions. Lorenz Hilty, professor at the University of Zurich, Switzerland, distinguishes three categories of impacts [8]:

1. Direct life cycle impacts arise from the production, the use, and the end of life of ICT products. These are detrimental impacts. For instance, ICTs are estimated to be currently responsible for between 2 and $4 \%$ of global GHG emissions [9-12].

2. Indirect enabling impacts emerge when deploying ICTs in our society. For example, optimization or substitution of some activities are generally positive for the environment as it reduces or replaces the use of another resource, whereas obsolescence or induction of new goods and services are clearly detrimental.

3. Indirect structural impacts manifest themselves at the macroeconomic level. If ICTs can potentially enable new beneficial business models like sharing economies, they also increase the dependency on complex and critical infrastructures and can be at the origin of long-term rebound effects [13]. An eloquent illustration of this effect concerns the energy use of ICTs. With the efficiency improvements realized between 2007 and 2012, electricity demand should have decreased by $89 \%$. However, the gains have allowed a more extensive usage, resulting in a final increase of $30 \%$ in the electricity demand for the same period [14].

The balance between the positive and negative impacts that ICTs have on the environment remains unclear and is debated in the literature. For instance, in a recent article aiming to answer the question "Does ICT reduce energy demand?" [15], the authors conclude that "the energy-increasing effects (direct effects and economic growth) of digitalization have been greater than the energy-reducing effects (energy efficiency increases and sectoral change)". On the contrary, a 2018 study from the private sector addressing the same issue, came to an opposite conclusion, claiming that "the ICT sector has turned its previous growing footprint into shrinking one despite a continuous increase in subscriptions and data traffic" [10]. This controversy highlights how difficult it is to properly evaluate the impacts of ICTs. It also illustrates the necessity to have good tools for fulfilling this goal.

\section{The Life Cycle Assessment: An Essential Compass Towards Sustainability?}

Among the range of environmental footprints associated with ICTs, direct impacts are the most straightforward to assess. The main tool used for that purpose is the life cycle assessment (LCA) [16]. This standardized methodology uses different environmental indicators [17], such as global warming potential, human toxicity or resources depletion, to quantify the direct impacts of a given product or service over its whole life cycle, i.e., from raw material extraction to manufacturing, distribution, use and end-of-life. In practice, LCA allows one to compare technical solutions or to highlight hot spots, namely critical contributors to environmental burdens, in order to choose or improve designs [18-20].

When performing LCA on electronic devices, it turns out that, beside batteries and displays, integrated and printed circuit boards are generally responsible for most of the impacts [21], as explained by Dr. Constantin Herrmann from Sphera Company, owner of state-of-the-art GaBi LCA database for electronics [22]. This is illustrated in Figure 1 for smartphones. Despite their low mass and tiny size, microelectronics components require highly energy-intensive processes and cleanroom facilities to be produced. Furthermore, large quantities of specific and harmful chemicals (e.g., fluorinated gazes to etch the silicon layers and substrates) and ultra-pure water are required [23]. 


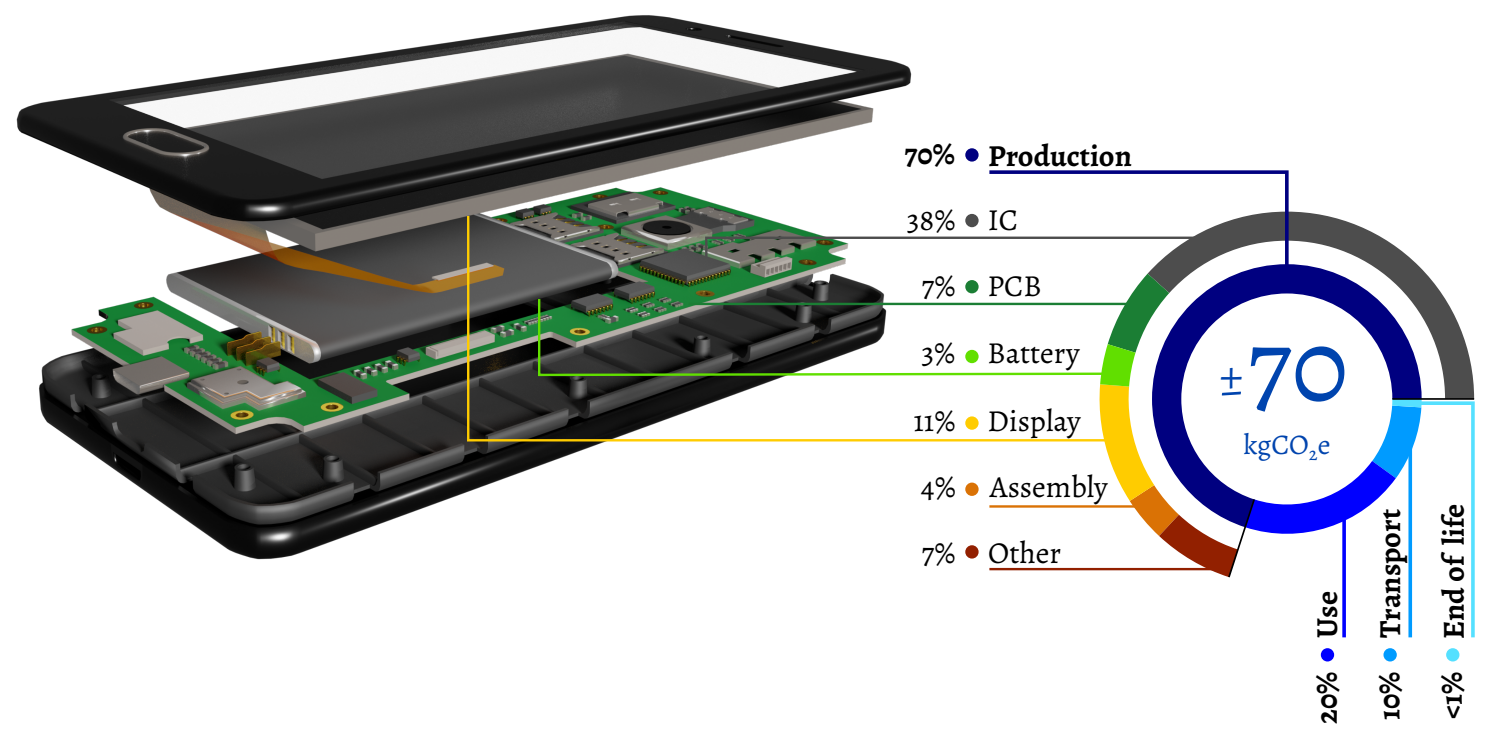

Figure 1. Typical carbon footprint (in $\mathrm{kg} \mathrm{CO}_{2}$ equivalent) generated over a smartphone lifetime. Integrated and printed circuit boards (IC and PCB) account for the largest share of the impacts. The values have been determined by the results presented in $[16,21]$.

As mentioned earlier with the example of the European Green Deal, digital transformation is often envisioned as a lever in the run towards carbon neutrality. In that scope, a pitfall is the transfer of environmental burdens from one step of the life cycle to another, cancelling the expected benefits. LCA appears to be essential in avoiding these prejudices. However, some huge challenges are still to be overcome in order to capture real environmental impacts with sufficient accuracy. Dr. Marie Garcia Bardon from IMEC research centre, Leuven, Belgium points out that the availability of up-to-date LCA databases is restrained by three main difficulties. First, she stresses the complexity of fabrication processes and the vast diversity of components on the market, worsened by very short innovation cycles. Second, she highlights that the microelectronics supply chain is particularly opaque due to the high number of stakeholders. Finally, she draws attention to the confidentiality issues and legal challenges related to intellectual properties, as most players have access to only part of the information.

Despite these difficulties, LCA is an essential tool, but it must first and foremost lead to re-thinking our way to perceive, develop and use electronic systems that support digital transformation from the very first steps of the design phase. Moreover, the monitoring of the technology impacts during its use phase must be continuously conducted. Regulation must be envisioned to keep possible rebound effects under control. Without a widespread paradigm shift, LCA will only show how unsustainable electronics are instead of being the compass towards a severe decrease of its environmental burden. Furthermore, as illustrated hereafter, ICTs also have complex social and geopolitical impacts that are not covered by the LCA methodology. Innovating in this field is not neutral and the complexity of its consequences must be better assessed by ICT actors.

\section{Innovating: A Task Not without Incidence}

With abundant energy and primary resources, the motivations behind innovations in ICT have been mainly focused on technical performances and economic profit. As discussed previously, this is far from enough considering humanity's sustainability challenge [24]. In view of these considerations, Philippe De Leener, professor of political economy at UCLouvain, Belgium, insists that innovations are not neutral: "When we win here [thanks to an innovation], others lose elsewhere, precisely where our eyes never travel". Due to these concealed environmental and social externalities, it leads him to say that the economy is the world of invisibility. Without paying attention to hidden consequences, "A 
solution can become part of the problem it aims to solve". Hence, he invites innovators to ask themselves, "What kind of world or society [they are] helping to build [when innovating]?".

Céline Verchère, professor of sociology and applied ethics at the University of Sherbrooke, Quebec, joins this view and adds that "the question of impact is inseparable from the notion of reflexivity, critical thinking and responsibility". She invites innovators to work from scratch with actors having different expertise, such as social scientists, to build a "responsible uses approach [to reduce the] gap between the projected impacts (the intended or desired effects) and the ones that will be realized". Since researchers are involved in the very first steps of the development process of new technologies, they have an influence on shaping the future of societies. Therefore, allocating time and energy towards more sustainable research is a powerful lever. However, she points out that "researchers alone cannot address all the issues of accountability and impact". A responsible governance is indeed essential to set up an appropriate societal and economic ecosystem for the development of sustainable innovations.

\section{The Need for New Business Models}

Innovating in a sustainable way requires new economic models favoring systemic thinking over the establishment of any technical solutions. The philosophy of circular economy aims precisely to meet that goal by avoiding the current linear cradle-to-grave product life flow [25,26]. Karel Van Acker, professor of circular economy, at KU Leuven, Belgium, recognizes three main strategies at the heart of this economic system.

1. The reduction in the production volume of digital devices can be achieved by repairing and sharing them.

2. The improvement of products' quality requires increasing lifetime (robustness, repairability, spare parts availability, etc.) and selecting the proper (lightweight, biodegradable, etc.) materials.

3. The renewal of products and materials implies that design favors reuse, remanufacturing or recycling. These solutions are sorted from the best to the worst in terms of revalorisation and energy consumption and should be considered as such when designing new products.

According to Prof. Van Acker, the products service system (functionality economy) is a model with high potential to induce circular economy. Instead of being sold to consumers, products are lent by companies in the scope of a service. It is therefore in their interest to extend as much as possible the lifetime of the objects involved in the service. However, again, without a proper analysis of the upstream impacts, the foreseen advantages could be compensated by the enabling and structural effects described before.

Circular economy presupposes that the amount of materials going out of the economic loop flow is minimised. However, the extraction of new materials will remain necessary. Presently, mining activities of many elements essential to ICTs are located in countries with low environmental regulations, causing severe pollution and leading to health issues for workers and the population living nearby. Furthermore, geopolitical issues emerge as some of these countries are in a position of monopoly, which threatens the integrity and supply chain of some industrial activities of concurrent countries. A wide overview of these problematics is given in the book "The rare metals war", from the French journalist Guillaume Pitron. To tackle these issues, Éric Pirard, professor of geological engineering at University of Liège, Belgium, considers that relocating mining activities in Western countries is essential. First, it will reduce ecological footprint thanks to stricter ecological norms, and second, it will rebalance geopolitical power relationships related to critical resources. His colleague, Johan Yans, professor of geology at University of Namur, Belgium, shares this vision but stresses that the challenge remains to better inform inhabitants of rich countries who are used to the NIMBY (not in my backyard) or BANANA (build absolutely nothing anywhere near anything) rhetoric. According to him, popularizing and teaching the notions regarding raw materials, going from the modes of extraction to their importance 
in global economy, is essential to ensure the minimal knowledge required to take reasoned decisions supported by the population.

These examples highlight that ICTs actors do not have all the levers to reach sustainability within the perimeters of their activities. Economics and society should evolve as well to shape an ideal framework enabling the needed global sustainable transformation. This is where ambitious actions taken by elected politicians have a critical role to play. Regarding the importance of the ICT sector, we believe it is their duty to support this change.

\section{Take Home Messages}

Based on the above discussions, we highlighted four major recommendations that should help researchers and industry stakeholders to innovate in a more sustainable way. Importantly, we advocate for including these multidisciplinary considerations in engineering curricula, since universities should not only train technicians but also citizens.

We must go beyond energy efficiency. At many governance levels, ICTs are perceived as a key tool to guide modern societies on the path to sustainability. However, the negative impacts of this sector are often overlooked, and the mainstream research direction to decrease them is predominantly paved with energy-efficiency objectives. This remains important, but we claim that it is far from sufficient, partly because of rebound effects. Indeed, historical trends show that such developments do not result in a global net decrease of energy consumption and carbon footprint $[14,27]$.

Indirect impacts should not be ignored. Besides direct impacts (incidence of the life cycle), ICTs also generate indirect ones (enabling of new usages, rebound effects, etc.). LCA is the gold standard to deal with the first kind of externality but is ineffective regarding the second. Indeed, indirect impacts are more than technological issues; they constitute a political issue requiring a constructive societal debate on which technologies are acceptable and which not. Nevertheless, the controversy regarding the deployment of 5G highlights the lack of methodologies to discuss, evaluate and predict the wide range of footprints of such developing technologies.

As innovators, we must consider social externalities related to the development and the exploitation of a technology. Without accounting for them, ICTs will keep contributing with unfair techno-economic systems. When talking about innovation, we must ask ourselves the central question: who are the winners, usually in the spotlight, but more importantly who are the losers, usually left in the shadow? We must question the invisible. In this vein, corporate social responsibility (CSR) programs aim to provide transparency in companies' activities. However the reports they deliver for that purpose often lack of credibility $[28,29]$. It highlights that the motivation behind CSR is often more about improving the brand image for the consumers than a real social involvement.

New business models are needed. The issue regarding CSR emphasizes the need for an innovation environment where the three former recommendations can be met. This could be achieved through frameworks such circular economy (and the related product as a service business model) or the open-source appropriate technology movement [30], for example. These paradigms intend to extend product lifetime and encourage the development of end-of-life scenarios predefined at the design phase. Tools such as the triple-layered business model canvas [31] and the sustainability guide [32] also offer good frameworks to consider social, economic and environmental impacts together, with, in target, the implementation of meaningful innovations with social-added value [26]. Nevertheless, this must be supported by ambitious political decisions to ensure effective uptake.

With these recommendations, ICT actors must help with transforming the system, not optimizing it. As explained by Eric Vidalenc, an expert in the economic and energy transition, ICTs are currently foreseen as a technological means to optimize the current techno-economic system. There is the belief that we could overcome the major social challenges through data management. However, regarding the size of these challenges, this is an illusion. The mindset of innovation players must move towards human-centered or biocentric ICT design to reduce social inequalities and the unbridled exploitation of natural 
resources. By turning our backs on this objective, ICTs will contribute to the acceleration of social, economic and environmental bankrupcy in our society.

To conclude in a more philosophical way, we choose a saying at the core of Ubuntu philosophy shared by Thierry Ngosso, professor of political philosophy at St Gallen University, Switzerland: "I am what I am because of who we all are". This points out the intensity and the inexorability of the link between everyone and everything. When we innovate, we have to raise our consciousness of all possible negative and positive impacts, since everything is interdependent.

Author Contributions: N.M. supervised the writing of the paper, T.P., G.L.B. and T.D. supervised the contact with the experts and N.M, T.P., G.L.B., T.D., G.S., A.P., D.B. and J.-P.R. contributed to the elaboration of the paper and participated actively in the intellectual endeavour having led to this opinion article. All authors have read and agreed to the published version of the manuscript.

Funding: This work was funded by F.R.S.-FNRS (FRIA grant to N.M., G.L.B. and T.D. and FNRS grant to A.P.), by the Fonds européen de développement régional (FEDER) and by the Wallonia within the Wallonie-2020.EU program.

Institutional Review Board Statement: Not applicable.

Informed Consent Statement: Not applicable.

Data Availability Statement: Not applicable.

Acknowledgments: The authors thank Lorentz Hilty, Constantin Herrmann, Sarah Boyd, Marie Garcia Bardon, Philippe De Leener, Céline Verchère, Karel Van Acker, Guillaume Pitron, Éric Pirard, Johan Yans, Eric Vidalenc and Thierry Ngosso for enlightening discussions during the SICT2020 summer school. Without their precious inputs, this opinion article would not have been possible.

Conflicts of Interest: The authors declare no conflict of interest.

\section{References}

1. Raymond, C.; Horton, R.M.; Zscheischler, J.; Martius, O.; AghaKouchak, A.; Balch, J.; Bowen, S.G.; Camargo, S.J.; Hess, J.; Kornhuber, K.; et al. Understanding and managing connected extreme events. Nat. Clim. Chang. 2020, 10, 611-621. [CrossRef]

2. Xu, Y.; Ramanathan, V.; Victor, D.G. Global warming will happen faster than we think. Nature 2018, 564, 30-32. [CrossRef] [PubMed]

3. Lenton, T.M.; Rockström, J.; Gaffney, O.; Rahmstorf, S.; Richardson, K.; Steffen, W.; Schellnhuber, H.J. Climate tipping points-Too risky to bet against. Nature 2019, 575, 592. [CrossRef] [PubMed]

4. United Nations. Paris Agreement. 2015. Available online: https://unfccc.int/files/essential_background/convention/ application/pdf/english_paris_agreement.pdf (accessed on 7 April 2021).

5. Luderer, G.; Vrontisi, Z.; Bertram, C.; Edelenbosch, O.Y.; Pietzcker, R.C.; Rogelj, J.; De Boer, H.S.; Drouet, L.; Emmerling, J.; Fricko, O.; et al. Residual fossil CO2 emissions in 1.5-2 ${ }^{\circ} \mathrm{C}$ pathways. Nat. Clim. Chang. 2018, 8, 626-633. [CrossRef]

6. Alkire, S.; Jahan, S. The New Global MPI 2018: Aligning with the Sustainable Development Goals. 2018. Available online: http:/ /hdr.undp.org/sites/default/files/2018_mpi_jahan_alkire.pdf (accessed on 7 April 2021).

7. European Commission. The European Green Deal. 2019. Available online: https://eur-lex.europa.eu/legal-content/EN/TXT/ ?qid=1596443911913\&uri=CELEX:52019DC0640\#document2(accessed on 7 April 2021).

8. Bieser, J.C.T.; Hilty, L.M. Assessing Indirect Environmental Effects of Information and Communication Technology (ICT): A Systematic Literature Review. Sustainability 2018, 10, 2662. [CrossRef]

9. Andrae, A.S.G.; Edler, T. On Global Electricity Usage of Communication Technology: Trends to 2030. Challenges 2015, 6, 117-157. [CrossRef]

10. Malmodin, J.; Lundén, D. The Energy and Carbon Footprint of the Global ICT and E\&M sectors 2010-2015. Sustainability 2018, 10, 3027. [CrossRef]

11. Belkhir, L.; Elmeligi, A. Assessing ICT global emissions footprint: Trends to 2040 \& recommendations. J. Clean. Prod. 2018, 177, 448-463. [CrossRef]

12. Freitag, C.; Berners-Lee, M.; Widdicks, K.; Knowles, B.; Blair, G.; Friday, A. The climate impact of ICT: A review of estimates, trends and regulations. arXiv 2021, arXiv:2102.02622.

13. Gossart, C. Rebound effects and ICT: A review of the literature. In ICT Innovations for Sustainability; Hilty, L.M., Aebischer, B., Eds.; Springer International Publishing: Cham, Switzerland, 2015; pp. 435-448. [CrossRef]

14. Aebischer, B.; Hilty, L.M. The Energy Demand of ICT: A Historical Perspective and Current Methodological Challenges. In ICT Innovations for Sustainability; Aebischer, B., Hilty, L.M., Eds.; Springer International Publishing: Cham, Switzerland, 2015; pp. 71-103. [CrossRef] 
15. Lange, S.; Pohl, J.; Santarius, T. Digitalization and energy consumption. Does ICT reduce energy demand? Ecol. Econ. 2020, 176, 106760. [CrossRef]

16. Ercan, M.; Malmodin, J.; Bergmark, P.; Kimfalk, E.; Nilsson, E. Life Cycle Assessment of a Smartphone. In ICT for Sustainability 2016; Atlantis Press: Dordrecht The Netherlands, 2016; pp. 124-133. [CrossRef]

17. Huijbregts, M.A.; Steinmann, Z.J.; Elshout, P.M.; Stam, G.; Verones, F.; Vieira, M.; Zijp, M.; Hollander, A.; van Zelm, R. ReCiPe 2016 A Harmonized Life Cycle Impact Assessment Method at Midpoint and Endpoint Level. RIVM Report 2016-0104. 2016. Available online: https:/ / www.rivm.nl/bibliotheek/rapporten/2016-0104.pdf (accessed on 7 April 2021).

18. Proske, M.; Sanchez, D.; Clemm, C.; Baur, S.-J. Life Cycle Assessment of the Fairphone 3; Fraunhofer IZM: Berlin, Germany, 2016. Available online: https://www.fairphone.com/wp-content/uploads/2020/07/Fairphone_3_LCA.pdf (accessed on 7 April 2021).

19. Bonvoisin, J.; Lelah, A.; Mathieux, F.; Brissaud, D. An integrated method for environmental assessment and ecodesign of ICT-based optimization services. J. Clean. Prod. 2014, 68, 144-154. [CrossRef]

20. Le Brun, G.; Raskin, J.-P. Material and manufacturing process selection for electronics eco-design: Case study on paper-based water quality sensors. Procedia CIRP 2020, 90, 344-349. [CrossRef]

21. Clément, L.-P.; Jacquemotte, Q.E.; Hilty, L.M. Sources of variation in life cycle assessments of smartphones and tablet computers. Environ. Impact Assess. Rev. 2020, 84, 106416. [CrossRef]

22. Sphera. GaBi Extension Database XI. 2020. Available online: http://www.gabi-software.com/international/databases/gabidatabases/electronics/ (accessed on 7 April 2021).

23. Boyd, S.B. Life-Cycle Assessment of Semiconductors; Springer: New York, NY, USA, 2012. Available online: https:/ / escholarship.org/ uc/item/8bv2s63d(accessed on 7 April 2021).

24. Kuhlman, T.; Farrington, J. What is sustainability? Sustainability 2010, 2, 3436-3448. [CrossRef]

25. Stahel, W.R. The circular economy. Nature 2016, 531, 435. [CrossRef] [PubMed]

26. Dyllick, T.; Rost, Z. Towards true product sustainability. J. Clean. Prod. 2017, 162, 346-360. [CrossRef]

27. Bol, D.; Pirson, T.; Dekimpe, R. Moore's Law and ICT Innovation in the Anthropocene. In Proceedings of the IEEE Design and Test in Europe Conference, Grenoble, France, 1-5 February 2021; Available online: https://dial.uclouvain.be/pr/boreal/object/ boreal\%3A243578/datastream/PDF_01/view (accessed on 7 April 2021).

28. Habek, P.; Wolniak, R. Assessing the quality of corporate social responsibility reports: The case of reporting practices in selected European Union member states. Qual. Quant. 2016, 50, 399-420. [CrossRef]

29. Lock, I.; Seele, P. The Credibility of CSR (corporate social responsibility) reports in Europe. Evidence from a quantitative content analysis in 11 countries. J. Clean. Prod. 2016, 122, 186-200. [CrossRef]

30. Pearce, J.M. The case for open source appropriate technology. Environ. Dev. Sustain. 2012, 14, 425-431. [CrossRef]

31. Joyce, A.; Paquin, R.L. The triple layered business model canvas: A tool to design more sustainable business models. J. Clean. Prod. 2016, 135, 1474-1486. [CrossRef]

32. EcoDesign Circle. The Sustainability Guide. 2021. Available online: https://sustainabilityguide.eu/ (accessed on 7 April 2021). 